\title{
STRATEGI ORANG TUA KRISTEN DALAM MEMBANGUN DISIPLIN ANAK
}

\author{
Kosma Manurung \\ Sekolah Tinggi Teologi Intheos Surakarta \\ kosmamanurung@sttintheos.ac.id
}

\begin{abstract}
This study intends to examine the strategies of parents in fostering child discipline in Christian families. The Bible places the primary responsibility for educating children with the parents. Children need the discipline to shape their character. In addition, discipline is also essential for children concerning social life, and discipline is the foundation that children need to achieve their future. The method used is descriptive and literature review. The results show that parents play a role in building their children's discipline. They have to develop communication using the love language of their children by making themselves role models that can be emulated by their children, providing space for children to grow and explore themselves, and through action firm in love.
\end{abstract}

Keywords: discipline, examplary, Christian family, parenting

\begin{abstract}
Abstrak. Penelitian ini bermaksud mengkaji strategi orang tua dalam menumbuh kembangkan disiplin anak di keluarga Kristen. Alkitab meletakan tanggung jawab utama untuk mendidik anak ada pada orang tua. Anak-anak memerlukan disiplin untuk membentuk karakter mereka. Selain itu disiplin juga penting bagi anak dalam kaitan dengan kehidupan sosial dan disiplin merupakan fondasi yang sangat dibutuhkan anak untuk meraih masa depan mereka. Metode yang digunakan adalah deksriptif dan kajian literatur. Berdasarkan hasil pembahasan artikel ini tersimpulkan bahwa para orang tua berperan dalam membangun disiplin anak mereka yaitu melalui membangun komunikasi dengan menggunakan bahasa cinta dari anak mereka, dengan menjadikan dirinya teladan yang bisa dicontoh oleh anaknya, memberikan ruang untuk anak bertumbuh serta mengeksplore dirinya, dan melalui tindakan tegas dalam kasih.
\end{abstract}

Kata Kunci: disiplin, keteladanan, keluarga Kristen, pola asuh

Aristoteles dalam Zoon Politicon mengambarkan bahwa manusia pada hakekatnya merupakan mahluk hidup yang tidak bisa hidup hanya dari dirinya sendiri. la selalu membutuhkan manusia lainnya (Putra, 2018). Ketika hidup bermasyarakat, manusia perlu diatur oleh suatu hukum agar tercipta keamanan dan ketertiban (Yudho and Tjandrasari, 2017). Keamanan dan ketertiban kelompok tersebut tergantung bagaimana disiplin dari para anggotanya. Semakin disiplin anggota masyarakatnya maka kehidupan mereka semakin aman dan tertib (Budijanto and Rini, 
2019). Keluarga merupakan bagian terkecil dari maysarakat, sebab itu disiplin sangat dibutuhkan di keluarga untuk menjaga keamanan dan ketertiban keluarga (Hutabarat, 2019).

Dari sudut pandang iman Kristen, pembentukan keluarga dimulai dari rencana Allah. Ketika seseorang masuk dalam hubungan keluarga maka orang tersebut sebetulnya secara pribadi sedang menggenapi rencana Allah sendiri (Manalu, 2020). Pernikahan lahir dari hati Allah. Dalam Kejadian 1: 26-28 disebutkan bahwa Allah sendiri yang merencanakan supaya manusia menikah dan beranak cucu (Budiyana, 2018) sehingga lahirlah keturunan yang diharapkan bisa mencermikan kepribadian Allah melalui sikap perilaku dan karakter mereka (Roy and Yosef, 2019).

Menjadi orang tua merupakan sebuah usaha berkelanjutan yang menuntut menuntut segenap upaya untuk terus berjuang melakukan yang terbaik bagi anak-anak (Nugroho, 2018). Orang tua perlu menyingkirkan kepentingan diri, menjauh dari kesenangan yang dinikmati sebelumnya, bahkan harus rela menderita demi si buah hati (Hartono, 2018). Orang tua juga dituntut untuk mendidik anak-anak agar di masa depan mereka bertumbuh menjadi manusia yang berguna baik bagi keluarga, gereja, masyarakat, dan bangsanya (Subianto, 2013).

Saat ini orang tua di seluruh dunia sedang menghadapi fase new normal dalam pandemi covid-19. Pada fase ini orang tua dituntut untuk bisa mengajarkan makna disiplin kepada anak-anak (Stevanus, 2018) 
agar mereka bisa menyesuaikan diri, tetap bisa belajar, bermain, dan menjalani hidup namun aman dari ancaman covid-19. Mereka bisa melindungi diri sendiri dan orang-orang di sekitarnya. Soesilo mengatakan bahwa disiplin bisa menjadi faktor penentu keberhasilan anak di era kenormalan baru (Soesilo, 2016). Penelitian ini bertujuan mengkaji bagaimana peran penting orang tua Kristen dalam menanamkan disiplin pada anak-anaknya dari sudut pandang Alkitab.

\section{METODE}

Dalam penelitian ini, peneliti menggunakan metode kualitatif dengan pendekatan deskriptif dan kajian literatur. Kedua pendekatan ini dipilih untuk memudahkan penyelesaian penelitian, memperdalam pengalian makna, dan memperjelas pemahaman yang peneliti bangun dalam artikel ini. Metode kualitatif memberikan makna pada hasil temuan dari penelitian (Zaluchu, 2020) dan gambaran realitas yang sebenarnya (Naat, 2020). Pendekatan deskriptif dipilih karena memang dalam metode ini para peneliti berusaha untuk memgambarkan peristiwa, kejadian, maupun fenomena baik itu bersifat nyata maupun rekaan (Yuliani, 2018). Pendekatan deskriptif peneliti gunakan dalam artikel ini dimulai dengan mengambarkan bagaimana pandangan Alkitab tentang tanggung jawab orang tua, mengambarkan hasil temuan penelitian, dan pembahasan peneliti dalam kaitan dengan tanggung jawab orang tua terhadap anak, pentingnya disiplin anak, dan bagaimana peran penting orang tua dalam membangun disiplin anak. 
Kajian literatur merupakan serangkaian proses yang dilakukan oleh peneliti berupa pengumpulan, pemilihan, dan pengelolahan data dari sumber-sumber tertulis berupa buku, artikel jurnal maupun literaur lainnya (Hutagalung, 2020). Dalam penelitian ini, kajian literatur yang peneliti gunakan bersumber dari buku dan artikel jurnal yang terkait dengan topik pembahasan guna memperkaya dan menguatkan pandangan-pandangan yang dikemukakan.

\section{HASIL}

Berikut adalah beberapa strategi yang bisa digunakan orang tua Kristen dalam membangun disiplin anak:

\section{Membangun Komunikasi Mengunakan Bahasa Cinta Anak}

Bahasa cinta anak adalah bahasa komunikasi anak. Ketika anak ingin berkomunikasi maka dia menggunakan bahasa cintanya. Bahasa cinta juga bisa dimaknai sebagai bahasa ekpresi dan penerimaan anak di mana anak-anak merasa paling disayangi oleh orang tua mereka. Komunikasi dengan bahasa cinta anak akan menghasilkan bonding yang begitu kuat dan mendalam antara anak dan orang tua. Ketika bonding ini sudah terbentuk maka peran orang tua untuk menanamkan disiplin pada anak akan lebih mudah. Anak-anak akan mendengarkan, menerima, meresapi, menerima, belajar serta melakukan nilai-nilai itu.

\section{Menjadi Teladan Bagi Anak}


Dunia anak adalah dunia yang penuh imajinasi yang melaluinya anak-anak mengaktualisasi diri. Dalam fase pertumbuhan tertentu misalnya anak-anak begitu mengidolakan pahlawan super dalam dunia fantasi mereka. Karena kehidupan itu nyata dan anak-anak hidup di dunia nyata, maka anak-anak membutuhkan contoh hidup yang bisa mereka teladani. Para orang tua harus menjadi contoh dan teladan hidup bagi anak-anaknya termasuk juga teladan dalam kaitan dengan disiplin. Orang tua yang hanya memberikan disiplin tapi gagal memberikan contoh lambat laun akan kehilangan kepercayaan maupun sikap hormat dari anakanaknya.

\section{Memberi Ruang pada Anak Untuk Bertumbuh}

Bagi anak kecil hampir setiap hari adalah proses belajar sesuatu yang baru. Mereka perlu waktu dan latihan berkali-kali untuk menguasai sesuatu, seperti berbicara, naik sepeda, dan lain-lain. Ada proses yang menuntut waktu, disiplin, dan kesabaran. Di sini orang tua dituntut ketelatenan, kesabaran, serta kesediaan memberikan ruang bagi anak. Termasuk dalam hal ini ketika anak melakukan kesalahan dan perlu mengulanginya berkali-kali. Alkitab pun meminta para orang tua untuk mengajarkan anak mereka secara berulang-ulang (UI. 6:6-9).

\section{Bertindak Tegas Dalam Kasih}

Anak-anak cenderung memusatkan dunia pada diri atau ego mereka. Egosentris anak ini bisa menjadi masalah ketika memasuki 
kehidupan social bersama orang lain. Di sinilah peran penting orang tua membangun disiplin diri anak itu sedari dini dan dalam kondisi tertentu harus tegas bahkan ada saatnya barang kali menggunakan rotan seperti yang kitab Amsal 23: 14. Namun itu harus dilakukan dalam kasih.

\section{PEMBAHASAN}

\section{Tanggung Jawab Orang Tua dalam Pandangan Alkitab}

Tangung jawab mencukupi kebutuhan anak

Alkitab memberikan tempat terhormat kepada para orang tua. Salah satu hukum dalam Sepuluh Hukum Taurat (Keluaran 20: 12) meminta setiap orang untuk menghormati orang tuanya (Soesilo, 2016). Namun untuk itu orang tua harus memikul tanggung jawab mencukupi kebutuhan anak dan mendidik anak tersebut (Hendra, 2018).

Orang tua perlu menyadari bahwa menjadi orang tua merupakan sebuah kehormatan yang Allah taruh pada setiap pasangan yang dipercayakan memiliki anak (Manalu, 2020). Mereka bertanggung jawab mencukupi kebutuhan anak dan mendidik mereka sesuai dengan jalanjalan Tuhan (Talupun, 2017). Kebutuhan itu antara lain rasa aman, hubungan sosial, kebutuhan fisik, kebutuhan mengaktualisasikan diri, dan lain-lain (Asaf, 2020). Orang tua harus memastikan ada tempat tinggal yang nyaman untuk anak bertumbuh, ada makanan bergizi di meja makan ketika anak-anak membutuhkan, dan mengusahakan pendidikan terbaik yang bisa diusahakan untuk anak tersayang (Siahaan, 2016). 


\section{Tanggung jawab mendidik anak}

Alkitab memberikan tanggung jawab utama mendidik anak kepada orang tuanya yang tidak bisa diwakilkan kepada orang lain (Sahartian, 2019) dan harus menjadi prioritas utama bagi para orang tua (Budiyana, 2018). Karena ketika orang tua gagal mendidik anak dengan benar maka banyak hal negatif yang akan menimpa anak itu sendiri, keluarga, bahkan pada lingkup yang lebih besar lagi (Diananda, 2019).

Pendidikan yang wajib diberikan orang tua kepada anak-anak melingkupi pendidikan yang mampu menjadikan anak tersebut di masa depan bisa mandiri dan menjadi manusia yang berkualitas (Nadeak, 2017). Selain itu pendidikan rohani juga perlu dilakukan orang tua Kristen karena akan membentuk karakter anak menjadi kuat, berdaya juang, rendah hati, dan disukai orang. Pendidikan rohani juga akan menjadikan anak kelak menjadi garam dan terang di manapun dia berada sehingga membawa keharuman Kristus (Roy and Yosef, 2019).

\section{Arti Penting Disiplin Bagi anak}

\section{Untuk Membentuk Karakter Anak}

Disiplin penting dan sangat dibutuhkan bagi anak terutama dalam proses membentuk karakter anak yang merupakan salah satu unsur penentu bagi kegagalan maupun keberhasilan seseorang (Sakti, 2018). Karakter bukanlah sesuatu yang ada begitu saja dalam diri seseorang melainkan merupakan sebuah proses panjang bagaimana seseorang merespon mengamati, belajar, dan merespon hal-hal yang terjadi didalam 
diri maupun disekitarnya (Tandy K, 2016). Alkitab mengambarkan karakter orang yang seperti ini sebagai orang yang membangun rumahnya di atas pasir yang karena hujan lebat rumah itu hancur karena tidak memiliki fondasi yang kokoh (Mat. 7: 26-27). Para orang tua perlu memahami, melatih, dan membangun disiplin diri anak-anak mereka sedini mungkin dengan lebih giat lagi sebagai bagian penting untuk membangun karakter yang baik dan kuat bagi anak mereka sehingga kelas ketika mereka dewasa mereka menjadi pribadi yang berguna bagi keluarga maupun sesama (Hartono, 2018).

\section{Dalam Kaitan dengan Kehidupan Sosial Anak}

Hal penting lainnya mengapa orang tua perlu membangun disiplin diri anak adalah terkait dengan kehidupan sosial anak (Nuhamara, 2018). Manusia pada kodratnya adalah makhluk yang tidak akan merasa nyaman hidup sendirian saja melainkan mahluk yang selalu hidup dalam kelompoknya (Simbolon, 2018). Kelompok disini bisa dimaknai dengan keluarga, kelompok bermain, komunitas sekolah, lingkungan kerja, komunitas gereja, teman perkumlulan, tingal bertetangga dan bermasyarakat (Kusumasondjaja, 2016). Untuk kenyamanan sebuah komunitas maupun kelompok biasanya ada aturan yang harus dipatuhi oleh setiap anggota kelompok itu kalau ada yang melanggar maka akan dijatuhkan sanksi-sanksi tertentu yang seudah diatur dan disepakati sebelumnya (Sudharma Putra, 2018). Anak kecil secara psikologis karena faktor usia masih melihat dalam bahwa segala sesuatu dalam kehidupan 
mereka masih berpusat pada diri mereka (Sa'adah, 2017). Keakuan atau egosentris mereka masih sangat tinggi. Jika seorang anak tidak pernah diajari disiplin diri yang benar maka anak tersebut akan berlaku semaunya saja. Kelak ketika dia mulai hidup dalam sebuah komunitas atau kelompok maka anak terjadi banyak gesekan dengan anak-anak lainnya (Suteja, 2017). Di sinilah pentingnya para orang tua secara khusus orang tua dari keluarga Kristen untuk mengajari anak mereka arti penting dari disiplin (Hutabarat, 2019).

\section{Terkait dengan Masa Depan Anak}

Hal penting lainnya mengapa para orang tua harus mengajarkan anak-anak mereka disiplin adalah terkait langsung dengan masa depan anak itu sendiri (Hendra, 2018). Disiplin diperlukan dalam belajar untuk mendapatkan nilai yang baik (Sari, 2019). Nilai yang baik di sekolah menengah akan membuka peluang yang lebih baik untuk ke perguruan tinggi favorit. Nilai baik di perguruan tinggi akan membuka peluang yang lebih besar untuk ditarik oleh perusahaan-perusahaan untuk bekerja ditempat mereka. Disiplin juga sangat dibutuhkan anak dimasa depan ketika mereka masuk dunia kerja. Apabila sering terlambat dan tidak bekerja dengan baik, maka hanya menunggu masalah waktu mereka akan dikeluarkan dari tempat pekerjaannya (Astria, 2018). Adapun alasan mengapa orang tua penting mengajarkan anak-anak mereka disiplin karena memang hal ini terkait langsung dengan kesuksesan anak-anak itu di masa depan mereka (Sidjabat, 2019). 


\section{Peran Orang Tua Dalam Membangun Disiplin Anak}

Membangun Komunikasi Melalui Bahasa Cinta Anak

Komunikasi memiliki peran menentukan bagi keluarga secara khusus bagi para orang tua untuk mereka mengkomunikasikan nilai-nilai pendidikan maupun mengkomunikasikan nilai-nilai penting untuk membangun kedisiplinan diri anak (Hadi, 2019). Meskipun sebuah nilainilai baik tujuannya, namun bila diajarkan melalui komunikasi yang keliru malah membuat anak itu menjauhkan diri dari berbagai nilai yang sedang diajarkan atau sampai pada titik jenuh akan nilai-nilai itu (Hafizah and Sari, 2019). Di sinilah orang tua penting memahami bahwa untuk membangun disiplin anak juga harus memahami cara mengkomunikasikan nilai-nilai itu kepada anak (Stevanus, 2018).

Bahasa cinta anak adalah bahasa yang anak-anak gunakan untuk berkomunikasi dengan orang tua mereka yang melaluinya anak-anak paling merasa diterima dan dihargai oleh para orang tuanya (Chapman and Campbell, 2018). Garry Chapman dan Ross Chambel dalam buku The 5 Love Languages of Children menawarkan solusi praktis untuk para orang tua secara khusus para orang tua di keluarga Kristen bagaimana berkomunikasi yang efektif dan menyentuh kepada anak-anak mereka yaitu melalui bahasa cinta anak (2018). Ada lima bahasa cinta anak yaitu sentuhan secara fisik, waktu kebersamaan berkualitas, perkataan yang meneguhkan, pemberian hadiah, dan tindakan melayani (Chapman and Campbell, 2018). Ketika para orang tua ingin memaksimalkan komunikasi 
dengan anak-anak mereka maka pergunakanlah bahasa cinta. Melalui bahasa cinta anak orang tua dapat membagikan nilai-nilai termasuk nilainilai praktis yang membangun disiplin diri anak.

\section{Menjadi Teladan Bagi Anak}

Dalam proses pertumbuhannya cara yang paling banyak dipakai oleh anak untuk belajar adalah dengan meniru (Mariyana and Setiasih, 2018) baik meniru segala perkataan yang dia dengar, maupun meniru gerakan atau cara melakukan sesuatu (Suteja, 2017). Sebab itu mereka membutuhkan teladan yang bisa mereka lihat secara dekat untuk belajar bagaimana bertindak atau merespon sesuatu (Putera, Wahyuni, and Ariani, 2019).

Teladan paling baik bagi anak-anak seharusnya dari orang tua agar sambil anak-anak belajar, orang tua bisa memantau secara langsung fase-fase tumbuh kembang anak itu (Cahyati and Kusumah, 2020). Terkait dengan membangun disiplin pada anak maka ketika sedang bersama anak para orang tua sebaiknya menggunakan kesempatan ini selain membangun ikatan yang kuat dengan anak juga ada baiknya menyisipkan nilai-nilai disiplin melalui tindakan-tindakan yang bisa dicontoh oleh anak (Hendra, 2018).

\section{Memberikan Ruang Bagi Anak Untuk Bertumbuh}

Cara lainnya yang bisa dilakukan oleh para orang tua untuk membangun disiplin anak adalah memberikan ruang untuk anak 
bertumbuh (Budiarti, 2018). Pertumbuhan itu bukanlah hal yang instan melainkan sebuah proses yang membutuhkan waktu (Syamsuriadi, 2018). Di dalam proses pertumbuhan tersebut barangkali ada banyak ketidaknyamanan, kesalahan, pengulangan, maupun pembelajaran yang terus menerus harus diusahakan oleh para orang tua agar anak itu menjadi lebih paham (Darmawan, 2019).

Memberikan anak ruang untuk bertumbuh memberikan keuntungan ganda yaitu dari perspektif anak maupun dari perspektif orang tua. Bagi orang tua adanya ruang bertumbuh ini membuat para orang tua menyadari bahwa anak-anak mereka bukanlah orang yang sempurna yang diajarin selalu langsung bisa melainkan para anak ini butuh waktu untuk belajar. Pemahaman ini menuntun para orang tua untuk lebih bersabar dan lebih bijaksana dalam mendidik anak mereka (Sudaryanti, 2017). Di sisi anak adanya ruang untuk bertumbuh ini membuat para anak merasa nyaman karena tidak merasa dipaksa untuk bisa, tidak merasa selalu dihakimi, dan juga anak-anak akan lebih memiliki keberanian untuk mengaktualisasikan diri (Hafizah and Sari, 2019). Terkait dengan membangun disiplin anak, adanya ruang untuk bertumbuh yang diberikan oleh para orang tua ini membuat anak melakukan segala perintah orang tua bukan karena unsur keterpaksaan semata melainkan anak-anak juga bisa meresapi makna dari disiplin yang sedang diajarkan kepada mereka (Emiyati, 2018).

Bertindak Tegas dalam Kasih 
Setiap orang tua pastinya memiliki keinginan untuk selalu menyenangkan dan membahagiakan anak-anak mereka. Namun apabila anak tidak pernah ditegur atau dimarah oleh orang tuanya maka ada kecenderungan anak itu akan bertumbuh menjadi anak yang manja dan sangat egois (Stevanus, 2018). Di sinilah ketegasan orang tua sangat diperlukan dan dalam kaitan dengan membangun disiplin anak orang dituntut untuk tegas, tindakan tegas bukan karena ingin ditakuti atau yang karena marah-marah melainkan tindakan tegas yang dalam kasih (Soesilo, 2016).

Masa kini dimana televisi dan internet telah mengambil alih peran orang tua di banyak keluarga karena yang menjadi guru bagi anak-anak mereka bukan lagi para orang tuanya melainkan televisi dan media telekomunikasi lainnya (Cahyati and Kusumah, 2020). Para orang tua harus segera menyadari ada bahaya yang sedang mengancam, menjerat, menipu, mengalihkan maupun meracuni pikiran anak-anak mereka akibat dari kurangnya pengawasan (Suteja, 2017). Untuk itu para orang tua dituntut segera mengambil alih kembali peran mereka sebagai orang tua yang bertindak dengan tegas mendisiplinkan anak-anak mereka sehingga anak-anak ini tidak terlena dengan berbagai masukan nilai-nilai dari media telekomunikasi yang dalam banyak hal justru menjerumuskan anak-anak dalam pemikiran yang salah sehingga melunturkan nilai-nilai kebenaran yang para orang tua tanamkan (Hutabarat, 2019). 


\section{KESIMPULAN}

Alkitab meletakan tanggung jawab utama untuk mendidik anak ada pada orang tua karena orang tua berperan penting dalam membangun disiplin diri anak-anak mereka. Berdasarkan hasil pembahasan dari penelitian artikel ini tersimpulkan bahwa peran orang tua dalam membangun disiplin anak mereka yaitu melalui membangun komunikasi dengan menggunakan bahasa cinta dari anak mereka, dengan menjadikan dirinya teladan yang bisa dicontoh oleh anaknya, memberikan ruang untuk anak bertumbuh serta mengeksplore dirinya, dan melalui tindakan tegas dalam kasih. Anak-anak memerlukan disiplin untuk membentuk karakter mereka. Selain itu disiplin juga penting bagi anak dalam kaitan dengan kehidupan sosial dan juga fondasi yang sangat dibutuhkan anak untuk meraih masa depan mereka. Selain membangun disiplin anak, tentunya para orang tua juga bertanggung jawab untuk mencukupi segala kebutuhan anak mereka.

Dengan kemampuan membangun disiplin anak yang baik, orang tua Kristen mestinya akan bisa membawa anak-anak tetap bertumbuh dengan baik di masa pandemic covid-19. Meskipun aktifitas masih lebih banyak di rumah dan menggunakan media daring, anak-anak bisa tetap bertumbuh dan berkembang dengan baik.

\section{DAFTAR PUSTAKA}

Asaf, A. S. (2020). Upaya Pemenuhan Kebutuhan Dasar Manusia. Jurnal IImiah Cakrawarti, 2(2), 26-31. https://doi.org/10.47532/jic.v2i2.126 
Astria, K. (2018). Pengaruh Disiplin Kerja Dan Motivasi Terhadap Kinerja Karyawan Pada PT. Bank Rakyat Indonesia Cabang Pamulang. Jurnal Mandiri, 2(1), 1-22. https://doi.org/10.33753/mandiri.v2i1.29

Budiarti, T. (2018). Model-Model Pendidikan Perdamaian Bagi Anak Dalam Konteks Gereja. Jurnal Jaffray, 16(1), 55-76. https://doi.org/10.25278/jj71.v16i1.280

Budijanto, O. W., \& Rini, N. S. (2019). Implementasi Mekanisme Pemberian Hukuman Disiplin di Kementerian Hukum dan HAM. Jurnal IImiah Kebijakan Hukum, 13(3), 283-310. https://doi.org/10.30641/kebijakan.2019.v13.283-310

Budiyana, H. (2018). Perspektif Alkitab Terhadap Keluarga Kristen. Regula Fidei: Jurnal Pendidikan Agama Kristen, 3(2), 581-589. https://doi.org/10.33541/regula\%20fidei.v3i2.983

Cahyati, N., \& Kusumah, R. (2020). Peran Orang Tua Dalam Menerapkan Pembelajaran Di Rumah Saat Pandemi Covid 19. JURNAL GOLDEN AGE, 4(1), 152-159.

Chapman, G., \& Campbell, R. (2018). The 5 love Languages of Children. ANDI Offset.

Darmawan, I. P. A. (2019). Pembelajaran Memorisasi Dalam Ulangan 6:69. EPIGRAPHE: Jurnal Teologi dan Pelayanan Kristiani, 3(1), 21-27. https://doi.org/10.33991/epigraphe.v3i1.50

Diananda, A. (2019). Psikologi Remaja Dan Permasalahannya. Journal Istighna, 1(1), 116-133. https://doi.org/10.33853/istighna.v1i1.20

Emiyati, A. (2018). Mendisiplin Anak Menurut Prinsip Kristen. Evangelikal: Jurnal Teologi Injili dan Pembinaan Warga Jemaat, 2(2), 147-156. https://doi.org/10.46445/ejti.v2i2.109

Hadi, N. (2019). Pendidikan Teologi Lintas Agama dalam Meraih Keluarga Bahagia (Analisis Teori Islam, Kristen, Hindu, Budha dan Konghucu). AL-USWAH: Jurnal Riset dan Kajian Pendidikan Agama Islam, 1(2), 67-87. https://doi.org/10.24014/au.v1i2.5224

Hafizah, E., \& Sari, P. (2019). Pola Komunikasi Keluarga Dalam Membentuk Karakter Anak. Raheema: Jurnal Studi Gender dan Anak, 6(1), 91-104.

Hartono, H. (2018). Membentuk Karakter Kristen Pada Anak Keluarga Kristen. Kurios, 2(1), 62-69. https://doi.org/10.30995/kur.v2i1.22

Hendra, V. (2018). Peran Orang Tua Dalam Menerapkan Kasih dan Disiplin Kepada Anak Usia 2-6 Tahun Sebagai Upaya Pembentukkan Karakter. Kurios, 3(1), 48-65. https://doi.org/10.30995/kur.v3i1.29

Hutabarat, O. R. (2019). Mendidik Anak Berkarakter Kristen Mengatasi Kekerasan. Voice of Wesley: Jurnal IImiah Musik dan Agama, 1(2). 
https://doi.org/10.36972/jvow.v1i2.12

Hutagalung, P. (2020). Pemuridan Sebagai Mandat Misi Menurut Matius 28:18-20. Pengarah: Jurnal Teologi Kristen, 2(1), 64-76. https://doi.org/10.36270/pengarah.v2i1.22

Kusumasondjaja, S. (2016). Identitas Sosial, Norma Kelompok, Kepercayaan Dan Online Helping Behavior Pada Komunitas Sosial Berbasis Facebook. Mix: Jurnal IImiah Manajemen, 6(2), 296-312. https://doi.org/10.22441/jurnal_mix

Manalu, E. O. (2020). Pengaruh Konseling Pranikah Terhadap Keutuhan Keluarga. ANTUSIAS Jurnal Teologi dan Pelayanan, 6(1), 16-31.

Mariyana, R., \& Setiasih, O. (2018). Penataan Lingkungan Belajar Terpadu Untuk Meningkatkan Potensi Kecerdasan Jamak Anak. Pedagogia, 15(3),

https://doi.org/10.17509/pdgia.v15i3.11020

Naat, D. E. (2020). Tinjauan Teologis-Dogmatis Tentang Sakramen Dalam Pelayanan Gerejawi. Pengarah: Jurnal Teologi Kristen, 2(1), 1-14. https://doi.org/10.36270/pengarah.v2i1.18

Nadeak, L. (2017). Mencintai Keluarga: Mengahayati Keadilan dan Belas Kasih. LOGOS: Jurnal Filsafat-Teologi, 14(2), 1-16.

Nugroho, W. A. (2018). Peranan Pendidikan Keluarga Tentang Kekudusan Hidup Menurut Roma 12:1-2. FIDEl: Jurnal Teologi Sistematika dan Praktika, 1(2), 185-198. https://doi.org/10.34081/fidei.v1i2.16

Nuhamara, D. (2018). Pengutamaan Dimensi Karakter Dalam Pendidikan Agama Kristen. Jurnal Jaffray, 16(1), 93-114. https://doi.org/10.25278/jj71.v16i1.278

Putera, D. A. D. A., Wahyuni, A. A. S., \& Ariani, N. K. P. (2019). Hubungan Pola Asuh Orang Tua Dengan Masalah Perilaku Dan Emosional Pada Anak Di Sd Saraswati 5 Denpasar. Jurnal Medika Udayana, 8(8), 1-6. https://doi.org/https://doi.org/10.24843/MU.2019.V8.i8.P3

Putra, A. M. (2018). Koreksi Persaudaraan: Tantangan dalam Mengembangkan Hidup Bersama. Societas Dei: Jurnal Agama dan Masyarakat, 4(2), 197-218. https://doi.org/10.33550/sd.v4i2.72

Roy, B., \& Yosef, A. (2019). Pertumbuhan Rohani Anak Dalam Keluarga Kristen Menurut Efesus 6:4. Jurnal The Way, 5(1), 52-69.

Sa'adah, U. (2017). Parenting Skills Orangtua dan Kesejahteraan Psikologis Anak. Psikoislamika : Jurnal Psikologi dan Psikologi Islam, 14(2), 5-15. https://doi.org/10.18860/psi.v14i2.6504

Sahartian, S. (2019). Pengaruh Pembinaan Rohani Keluarga Terhadap Karakter Pemuda Berdasarkan Kolose 2: 6-10 Di GBAP Surakarta. 
FIDEl: Jurnal Teologi Sistematika dan Praktika, 2(1), 20-39. https://doi.org/10.34081/fidei.v2i1.30

Sakti, B. P. (2018). Indikator Pengembangan Karakter Siswa Sekolah Dasar. Magistra, 29(101), 1-10. https://doi.org/10.31227/osf.io/pucw9

Sari, D. N. (2019). Upaya Preventif Guru Kristen Dalam Menghadapi Degradasi Moral Anak. Visio Dei: Jurnal Teologi Kristen, 1(1), 79100. https://doi.org/10.35909/visiodei.v1i1.11

Siahaan, H. E. R. (2016). Hikmat Sebagai Implikasi Pendidikan Kristiani: Refleksi 1 Raja-raja 3:1-15. DUNAMIS: Jurnal Penelitian Teologi dan Pendidikan Kristiani, 1(1), 15-30. https://doi.org/10.30648/dun.v1i1.99

Sidjabat, B. S. (2019). Penguatan Guru Pak Untuk Pendidikan Karakter: Evangelikal: Jurnal Teologi Injili dan Pembinaan Warga Jemaat, 3, 30-48.

Simbolon, E. T. (2018). Pentingnya Keterampilan Sosial Dalam Pembelajaran. Jurnal Christian Humaniora, 2(1), 40-52. https://doi.org/10.46965/jch.v2i1.108

Soesilo, Y. (2016). Penggunaan Rotan Dalam Pendisiplinan Anak Menurut Kitab Amsal 23:13-14. DUNAMIS: Jurnal Penelitian Teologi dan Pendidikan Kristiani, 1(1), 1-14. https://doi.org/10.30648/dun.v1i1.98

Stevanus, K. (2018). Tujuh Kebajikan Utama Untuk Membangun Karakter Kristiani Anak. BIA': Jurnal Teologi dan Pendidikan Kristen Kontekstual, 1(1), 79-95. https://doi.org/10.34307/b.v1i1.21

Subianto, J. (2013). Peran Keluarga, Sekolah, Dan Masyarakat Dalam Pembentukan Karakter Berkualitas. Edukasia: Jurnal Penelitian Pendidikan Islam, 8(2), 331-354. https://doi.org/10.21043/edukasia.v8i2.757

Sudaryanti, S. (2017). Mendidik Anak Menjadi Manusia Yang Berkarakter. Jurnal Pendidikan Anak, 3(2), 506-517. https://doi.org/10.21831/jpa.v3i2.11706

Sudharma Putra, I. B. (2018). Sosial Control: Sifat Dan Sanksi Sebagai Sarana Kontrol Sosial. Vyavahara Duta, 13(1), 27-32. https://doi.org/10.25078/vd.v13i1.529

Suteja, J. (2017). Dampak Pola Asuh Orang Tua Terhadap Perkembangan Sosial-Emosional Anak. Awlady: Jurnal Pendidikan Anak, 3(1), 1-14. https://doi.org/10.24235/awlady.v3i1.1331

Syamsuriadi, S. (2018). Manajemen Pendidikan Anak Usia Dini Berbasis Pembelajaran Berpusat Pada Anak: Perspektif Naturalisme Romantik. Adaara: Jurnal Manajemen Pendidikan Islam, 6(1), 571-583. https://doi.org/10.35673/ajmpi.v6i1.288

Talupun, J. S. (2017). Resensi: Families in Ancient Israel The Family, 
Religion, and Culture. Gema Teologika, 2(1), 97. https://doi.org/10.21460/gema.2017.21.297

Tandy K, P. (2016). Karakter Pendidik Kristen Dan Nilai-Nilai Kerajaan Allah Analisis Injil Matius. Regula Fidei: Jurnal Pendidikan Agama Kristen, $1(1)$, 163-188. https://doi.org/10.33541/regula\%20fidei.v1i1.147

Yudho, W., \& Tjandrasari, H. (2017). Efektivitas Hukum Dalam Masyarakat. Jurnal Hukum \& Pembangunan, 17(1), 57. https://doi.org/10.21143/jhp.vol17.no1.1227

Yuliani, W. (2018). Metode Penelitian Deskriptif Kualitatif Dalam Perspektif Bimbingan Dan Konseling. Quanta STKIP Siliwangi Journals, 2(2), 83-93. https://doi.org/10.22460/q.v2i2p83-91.1641

Zaluchu, S. E. (2020). Strategi Penelitian Kualitatif dan Kuantitatif Di Dalam Penelitian Agama. Evangelikal: Jurnal Teologi Injili dan Pembinaan Warga Jemaat, 4(1), 28-38. https://doi.org/10.46445/ejti.v4i1.167 